Cahiers $d u$ MONDE RUSSE

\section{Cahiers du monde russe}

Russie - Empire russe - Union soviétique et États indépendants

45/3-4 | 2004

Varia

\title{
Georgij Efron, Dnevniki v dvuh tomah
}

\section{Michel Aucouturier}

\section{OpenEdition \\ Journals}

Édition électronique

URL : https://journals.openedition.org/monderusse/4210

DOI : $10.4000 /$ monderusse. 4210

ISSN : $1777-5388$

\section{Éditeur}

Éditions de l'EHESS

\section{Édition imprimée}

Date de publication : 1 juillet 2004

Pagination : 722-723

ISBN : 2-7132-2009-2

ISSN : $1252-6576$

\section{Référence électronique}

Michel Aucouturier, «Georgij Efron, Dnevniki v dvuh tomah », Cahiers du monde russe [En ligne], 45/3-4 | 2004, mis en ligne le 03 juin 2009, consulté le 03 septembre 2022. URL : http://

journals.openedition.org/monderusse/4210; DOI : https://doi.org/10.4000/monderusse.4210

Ce document a été généré automatiquement le 3 septembre 2022

Tous droits réservés 


\title{
Georgij Efron, Dnevniki v dvuh tomah
}

\author{
Michel Aucouturier
}

\section{RÉFÉRENCE}

Georgij EFRON, Dnevniki v dvuh tomah. T. 1 : 1940-1941, t. 2 : 1941-1943. Édition, préf. et postf. de E. B. KORKINA, V. K. LOSSKAJA [Véronique Lossky]. Postface de Tat'jana GORJAEVA. Moscou, Vagrius, 2004, $559+368$ p.

1 On connait le destin tragique de Georgij Efron, troisième et dernier enfant de Marina Cvetaeva, connu sous le nom affectueux de Mur (d'après « le chat Murr » de Hoffmann) que lui avait donné sa mère: né en Tchécoslovaquie en 1925, élevé en France jusqu’à 14 ans, il a été emmené par elle en URSS pour y rejoindre sa sœur aînée et son père, repartis deux ans plus tôt, - et assister presque aussitôt à leur arrestation. Évacuée avec son fils dans le bourg tatare d'Elabouga, où elle se trouvait sans ressources et dans un isolement total, Marina Cvetaeva y avait mis fin à ses jours le 31 août 1941. Abandonné à lui-même, le jeune garçon, alors âgé de seize ans, d'abord évacué à Tachkent, avait pu revenir à Moscou et y commencer des études à l'Institut de littérature, mais il avait été presque aussitôt mobilisé et envoyé sur le front de Biélorussie, où il est mort le 7 juillet 1944, à l'âge de dix-neuf ans.

Enfant, puis adolescent d'une étonnante maturité, Mur avait commencé dès son arrivée à Moscou à tenir un journal intime quotidien, qu'il a poursuivi au moins jusqu'à son départ à l'armée. C'est ce journal, rédigé alternativement en russe et en français, et presque intégralement conservé aux Archives d'État de littérature et d'art à Moscou (RGALI) que publient aujourd'hui, dans le texte original, deux spécialistes de l'œuvre de la poétesse, Elena Korkina et Véronique Lossky, qui a transcrit et traduit en russe la partie française du manuscrit.

3 Cette publication est un événement. Tenu au jour le jour, avec une minutieuse précision, le journal de Mur apporte d'abord une information détaillée sur la vie quotidienne de 
Marina Cvetaeva au cours de la période qui va de son retour en URSS jusqu'à son suicide : son dénuement, son isolement croissant, ses épuisantes démarches à Moscou pour se loger, en évacuation pour trouver du travail et subvenir à ses besoins et à ceux de son fils, ressortent avec une cruelle netteté. Par-delà même le destin de la poétesse, le journal donne une image d'une saisissante précision de ce qu'a pu être la vie quotidienne de l'URSS du temps de guerre, avec ses queues, ses gares et ses trains bondés, son marché noir et ses administrations paperassières.

Ces détails quotidiens, enregistrés avec minutie, pourraient être lassants si, à travers eux, nous n'avions constamment sous les yeux l'image de cet enfant trop avancé pour son âge, puis de cet adolescent luttant obstinément pour sa survie quotidienne au milieu des pires difficultés, aux côtés de sa mère ou seul, sans jamais se décourager ou même se laisser aller, et sans jamais perdre de vue un besoin obstiné de perfectionnement intellectuel. De sa précoce maturité témoignent les nombreux écrivains et penseurs (Valéry, Malraux, Čehov, Leonov, Nietzsche, etc.) dont la lecture, en français ou en russe, occupe une place importante dans sa vie, et qu'il commente dans son journal. Soit par prudence, soit parce qu'il pouvait savoir d'avance à quoi s'en tenir, Mur ne porte pas de jugement sur la vie soviétique, qu'il a pourtant dû trouver bien différente de celle qu'il a connue en France. Mais ses commentaires sur la situation internationale, l'aggression allemande, le rapprochement attendu et souhaité de l'URSS et des démocraties occidentales, les succès des Alliés en Afrique du Nord ou en Italie, qu'il suit à travers les émissions étrangères - et en particulier celles de la Voix de la France libre à Londres - à côté des victoires de l'Armée rouge, témoignent d'un esprit critique que n'entame pas son patriotisme russe et soviétique.

5 Il y a là un document humain émouvant, qui ajoute une nuance tragique supplémentaire à ce que l'on savait de la vie personnelle et familiale de Marina Cvetaeva, en même temps qu'un document social et historique du plus grand intérêt. 